\title{
Evaluation of Non-Basal Slip Activity in Rolled Mg-Li Alloys*1
}

\author{
Haruka Miyano $^{1, * 2}$, Keisuke Takemoto ${ }^{1, * 3}$, Masayuki Tsushida ${ }^{2}$, Hiromoto Kitahara ${ }^{3,4, * 4}$ and Shinji Ando ${ }^{4}$ \\ ${ }^{1}$ Graduate School of Science and Technology, Kumamoto University, Kumamoto 860-8555, Japan \\ ${ }^{2}$ Technical division, Kumamoto University, Kumamoto 860-8555, Japan \\ ${ }^{3}$ Institute of Industrial Nanomaterials, Kumamoto University, Kumamoto 860-8555, Japan \\ ${ }^{4}$ Magnesium Research Center, Kumamoto University, Kumamoto 860-8555, Japan
}

Tensile tests of rolled $\mathrm{Mg}-6.2 \mathrm{~mol} \% \mathrm{Li}$ and $\mathrm{Mg}-11.7 \mathrm{~mol} \% \mathrm{Li}$ alloys were carried out at room temperature to clarify effects of lithium addition on the relationship between mechanical properties and activities of slip systems. Ductility increased with increasing lithium content. $0.2 \%$ proof stress increased when $6.2 \mathrm{~mol} \% \mathrm{Li}$ was added. However, $\mathrm{Mg}-11.7 \mathrm{~mol} \% \mathrm{Li}$ showed low $0.2 \%$ proof stress, compared to pure magnesium. On the other hand, maximum stress decreased with increasing lithium content. Frequency of non-basal slips increased with increasing lithium content. Also, first order pyramidal $\langle\mathrm{c}+\mathrm{a}\rangle$ slip showed the highest frequency among non-basal slips in $\mathrm{Mg}-\mathrm{Li}$ alloys. Critical resolved shear stresses for non-basal slips, which were reduced by lithium addition, increased ductility but decreased tensile strength of magnesium. [doi:10.2320/matertrans.L-M2021826]

(Received January 19, 2021; Accepted April 5, 2021; Published June 25, 2021)

Keywords: rolling texture, pyramidal slip, prismatic slip, basal slip, CRSS

\section{Introduction}

Main slip system of magnesium is basal slip (BS). However, BS only offers two independent slip systems, and the number of basal slip is insufficient for von Mises criterion. For that reason, room temperature formability of magnesium is limited. Many magnesium alloys containing rare earth elements have been studied to improve the low ductility. ${ }^{1-5)}$ Sandlöbes et al. ${ }^{1)}$ reported that $\mathrm{Mg}-0.84 \mathrm{~mol} \% \mathrm{Y}$ alloy polycrystals had five times higher ductility than pure magnesium and strength as same as pure magnesium at room temperature. In the Ref. 1), the high ductility was explained by the high activity of $\langle\mathrm{c}+\mathrm{a}\rangle$ dislocations due to yttrium addition. Rikihisa et ll $^{2)}$ performed tensile tests of $\mathrm{Mg}-(0.6-$ $1.3) \mathrm{mol} \% \mathrm{Y}$ alloy single crystals in the directions of parallel to basal planes and reported that $\mathrm{Mg}-(0.6-0.9) \mathrm{mol} \% \mathrm{Y}$ alloy single crystals yielded due to $\{10 \overline{1} 1\}\langle 11 \overline{2} 3\rangle$ first order pyramidal $\langle\mathrm{c}+\mathrm{a}\rangle$ slip (FPCS). Also, yttrium addition was found to increase the activity of FPCS based on results of tensile tests of $\mathrm{Mg}-0.9 \mathrm{~mol} \% \mathrm{Y}$ alloy polycrystals with basal texture. Therefore, they concluded that the high ductility of $\mathrm{Mg}-\mathrm{Y}$ alloys resulted from the high activity of FPCS in Ref. 2).

Ando et $\left.a l .{ }^{6}\right)$ reported that $\mathrm{Mg}-(3.5-14.0) \mathrm{mol} \% \mathrm{Li}$ alloy single crystals yielded due to second order pyramidal $\langle c+a\rangle$ slip (SPCS) in [1120] tensile tests and that yield stress decreased with increasing lithium content. Also, Yoshinaga et $a .^{7)}$ and Ahmadieh et al. ${ }^{8)}$ individually reported that the critical resolved shear stress (CRSS) for prismatic slip (PS) decreased with increasing lithium content. Therefore, the ductility of magnesium was expected to increase by improving activity of non-basal slips due to lithium addition. However, activated slip systems in $\mathrm{Mg}-\mathrm{Li}$ alloy polycrystals

\footnotetext{
${ }^{* 1}$ This Paper was Originally Published in Japanese in J. JILM 70 (2020) 117-121.

${ }^{* 2}$ Graduate Student, Kumamoto University

${ }^{* 3}$ Graduate Student, Kumamoto University, Present address: AICHI STEEL CORPORATION, Tokai 476-8666, Japan

${ }^{* 4}$ Corresponding author, E-mail: kitahara@msre.kumamoto-u.ac.jp
}

and effects of lithium addition on the slip system are unclear. The present study was carried out to clarify the effects of lithium addition on the relationship between mechanical properties and activities of slip systems in $\mathrm{Mg}-\mathrm{Li}$ alloy polycrystals.

\section{Experimental Procedures}

Two types of Mg-Li alloys with different lithium contents were cast from $99.9 \%$ or more lithium (Nacalai Tesque Inc.) and pure magnesium using a high frequency induction heating vacuum furnace; the chemical composition of pure magnesium are shown in Table 1 . Two $\mathrm{Mg}-\mathrm{Li}$ alloys were identified to be $\mathrm{Mg}-6.2 \mathrm{~mol} \% \mathrm{Li}$ and $\mathrm{Mg}-11.7 \mathrm{~mol} \% \mathrm{Li}$ by ICP emission spectroscopy. $\mathrm{Mg}-\mathrm{Li}$ alloys were hot-rolled and annealed to obtain mean grain size of approximately $50 \mu \mathrm{m} . \mathrm{Mg}-\mathrm{Li}$ alloys were hot-rolled at $523 \mathrm{~K}$ with rolling reduction approximately $10 \%$ per pass and were subsequently water quenched; the total reduction was $72 \% . \mathrm{Mg}-$ $6.2 \mathrm{~mol} \% \mathrm{Li}$ alloys were annealed at $723 \mathrm{~K}$ for $1.5 \mathrm{ks}$, while $\mathrm{Mg}-11.7 \mathrm{~mol} \% \mathrm{Li}$ alloys were annealed at $748 \mathrm{~K}$ for $1.2 \mathrm{ks}$, in an argon atmosphere.

Figure 1 shows a schematic illustration of tensile specimen; tensile direction was parallel to rolling direction of

Table 1 Chemical composition of pure magnesium ingots. (mass\%)

\begin{tabular}{|c|c|c|c|c|c|c|c|}
\hline $\mathrm{Zn}$ & $\mathrm{Ni}$ & $\mathrm{Si}$ & $\mathrm{Mn}$ & $\mathrm{Fe}$ & $\mathrm{Cu}$ & $\mathrm{Al}$ & $\mathrm{Mg}$ \\
\hline 0.0607 & 0.1017 & 0.3875 & 0.0804 & 0.1178 & 0.1231 & 0.2911 & Bal. \\
\hline
\end{tabular}

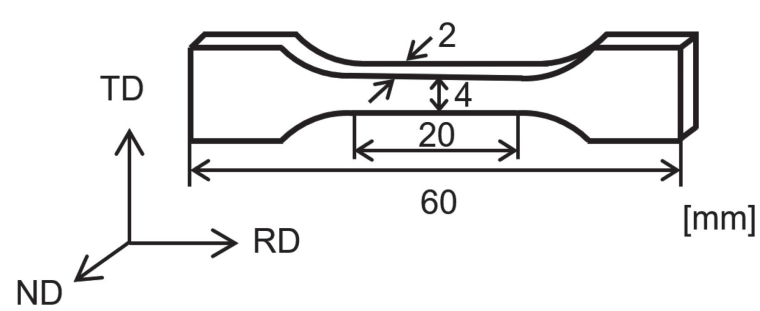

Fig. 1 Schematic illustration of tensile test specimen. 
(a) Mg-6.2mol\%Li

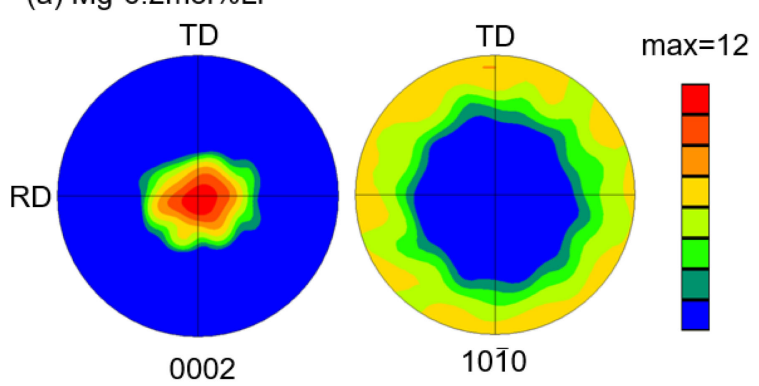

(b) $\mathrm{Mg}-11.7 \mathrm{~mol} \% \mathrm{Li}$

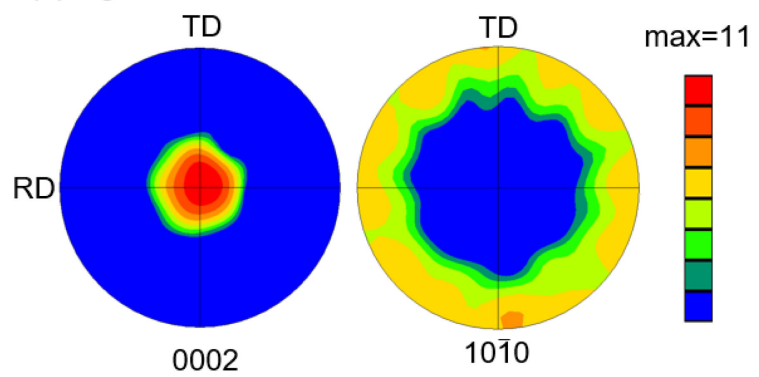

Fig. 2 (0002) and $\{10 \overline{1} 0\}$ pole figures of (a) $\mathrm{Mg}-6.2 \mathrm{~mol} \% \mathrm{Li}$ and (b) $\mathrm{Mg}-$ $11.7 \mathrm{~mol} \% \mathrm{Li}$ alloys before tensile tests.

sheets (RD). Tensile specimens were mechanically polished using emery paper (\#400-4000), an MD-Nap (Struers), and diamond spray of 3, 1 and $0.25 \mu \mathrm{m}$ (Struers). Specimen surfaces after mechanical polishing were chemically polished to mirror using a polishing cloth soaked in a solution $\left(\mathrm{HNO}_{3}: \mathrm{H}_{2} \mathrm{O}_{2}: \mathrm{C}_{2} \mathrm{H}_{5} \mathrm{OH}=5: 7: 20\right)$ and were corroded with a picric acid solution $\left(\mathrm{HOC}_{6} \mathrm{H}_{2}\left(\mathrm{NO}_{2}\right)_{3}: \mathrm{CO}_{3} \mathrm{COOH}: \mathrm{C}_{2} \mathrm{H}_{5} \mathrm{OH}\right.$ : $\mathrm{H}_{2} \mathrm{O}=5: 10: 60: 10$ ). For trace analysis, initial crystal orientations of the normal direction of specimens (ND) were analyzed using a FE-SEM (JEOL Ltd. JIB-4601F) and an EBSD camera (TexSEM Laboratories corp.) before tensile tests. Tensile tests were carried out at $298 \mathrm{~K}$ with the initial strain rate, $\dot{\varepsilon}=8.4 \times 10^{-4} / \mathrm{s}$. Slip lines were observed using a Nomarski type optical microscope (Nikon corp. ECLIPSE LV 150N) after tensile tests. Slip systems were identified at each strain, and Schmid factor for activated slip systems were determined using the initial crystal orientation analyzed by EBSD before tensile tests.

\section{Results}

Figure 2 shows (0002) and $\{10 \overline{10}\}$ pole figures of (a) $\mathrm{Mg}_{-}$ $6.2 \mathrm{~mol} \% \mathrm{Li}$ and (b) $\mathrm{Mg}-11.7 \mathrm{~mol} \% \mathrm{Li}$ alloys. Both $\mathrm{Mg}-\mathrm{Li}$ alloys showed basal texture whose c-axe are oriented parallel to ND. Similar texture was reported in pure magnesium; the maximum intensity of texture was approximately $23 .{ }^{2)}$ The maximum intensity was 12 in $\mathrm{Mg}-6.2 \mathrm{~mol} \% \mathrm{Li}$ alloys and 11 in $\mathrm{Mg}-6.2 \mathrm{~mol} \% \mathrm{Li}$ alloys. Therefore, lithium addition was found to make basal texture weaker in magnesium. Also, the difference in the lithium additions barely affected the maximum intensity of the basal texture.

Figure 3 shows typical stress-strain curves of $\mathrm{Mg}-\mathrm{Li}$ alloys. The results ${ }^{2}$ on pure magnesium and $\mathrm{Mg}-0.9 \mathrm{~mol} \% \mathrm{Y}$ are also shown for comparison. The horizontal and vertical arrows in Fig. 3 indicate $0.2 \%$ proof stress and fracture

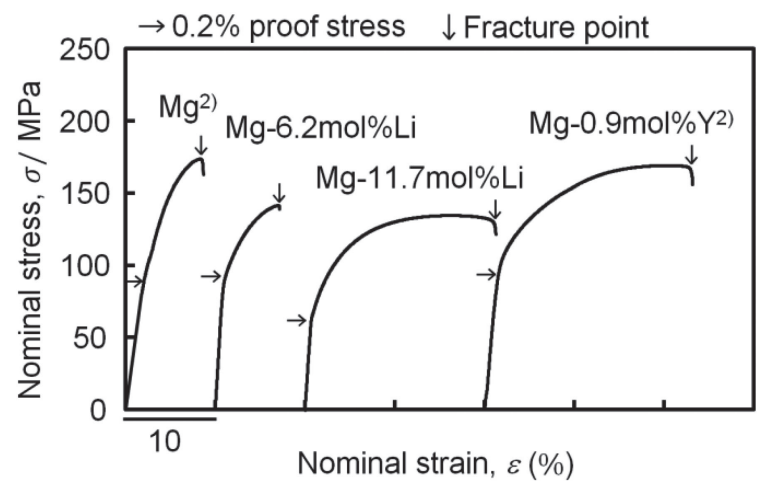

Fig. 3 Stress-strain curves of pure magnesium, Mg-6.2 mol\%Li, $\mathrm{Mg}-$ $11.7 \mathrm{~mol} \% \mathrm{Li}$ and $\mathrm{Mg}-0.9 \mathrm{~mol} \% \mathrm{Y}$ alloys.

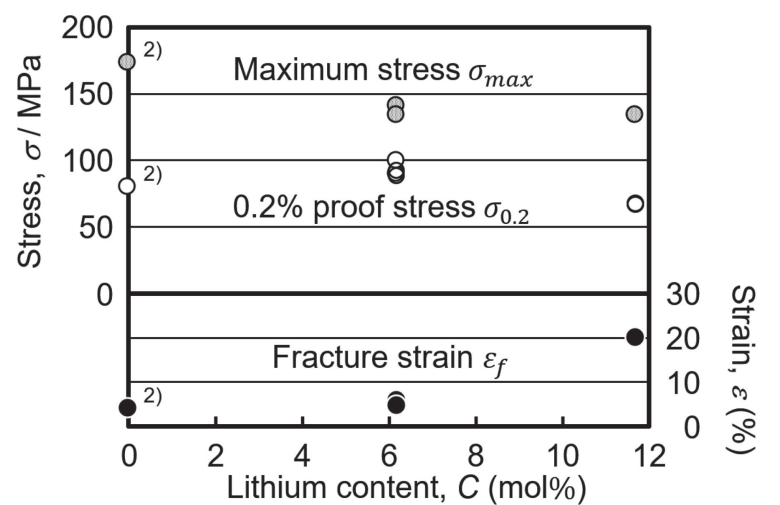

Fig. $40.2 \%$ proof stress, maximum stress, fracture strain as a function of lithium content in $\mathrm{Mg}-\mathrm{Li}$ alloys. (a) Mg-6.2mol\%Li $\varepsilon=3.6 \%$

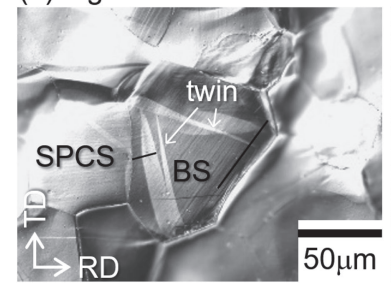

(b) $\mathrm{Mg}-11.7 \mathrm{~mol} \% \mathrm{Li} \varepsilon=5.9 \%$

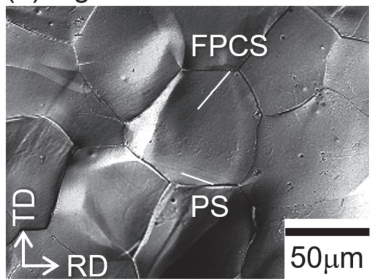

Fig. 5 Optical micrographs of slip lines and $\{10 \overline{1} 2\}$ twins on the surfaces of (a) $\mathrm{Mg}-6.2 \mathrm{~mol} \% \mathrm{Li}$ and (b) $\mathrm{Mg}-11.7 \mathrm{~mol} \% \mathrm{Li}$. Slip lines were crystallographically analyzed and identified to the corresponding slip system: basal slip (BS); prismatic slip (PS); first order $\langle c+a\rangle$ pyramidal slip (FPCS); and second order $\langle\mathrm{c}+\mathrm{a}\rangle$ pyramidal slip (SPCS).

points. Two Mg-Li alloys show low work hardening rates until $6.0 \%$ tensile strain, compared to pure magnesium. $\mathrm{Mg}-$ $6.2 \mathrm{~mol} \% \mathrm{Li}$ alloys broke at approximately $6.0 \%$ tensile strain, while $\mathrm{Mg}-11.7 \mathrm{~mol} \% \mathrm{Li}$ alloys showed almost constant flow stress with no break. Figure 4 shows changes in $0.2 \%$ proof stress, maximum stress and fracture strain, as a function of lithium content in $\mathrm{Mg}-\mathrm{Li}$ alloys. $0.2 \%$ proof stress increased in $6.2 \mathrm{~mol} \%$ lithium addition, but decreased in $11.7 \mathrm{~mol} \%$ lithium addition. Also, maximum stress decreased, and ductility increased, with increasing lithium content.

Figure 5 shows optical micrographs of slip lines in $\mathrm{Mg}-\mathrm{Li}$ alloys. Slip lines caused by BS, PS, FPCS and SPCS and $\{10 \overline{1} 2\}$ twins with lenticular morphology were observed in each $\mathrm{Mg}-\mathrm{Li}$ alloy. BS slip lines appeared in many grains and occupied each grain. FPCS slip lines finer than BS slip lines 


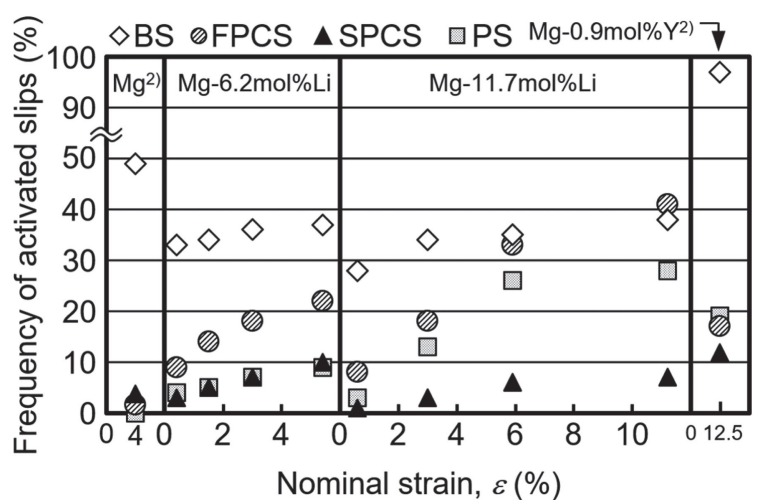

Fig. 6 Relationship between frequency of activated slips and nominal strain in pure magnesium, $\mathrm{Mg}-6.2 \mathrm{~mol} \% \mathrm{Li}, \mathrm{Mg}-11.7 \mathrm{~mol} \% \mathrm{Li}$ and $\mathrm{Mg}-$ $0.9 \mathrm{~mol} \% \mathrm{Y}$ alloys.

never occupied each grain but locally appeared near grain boundaries, as shown in Fig. 5(b). On the other hand, both PS and SPCS slip lines were short, and most of them were observed near grain boundaries only. The number fraction of grains where $\{10 \overline{1} 2\}$ twins were activated decreased with increasing lithium content; the frequency was $50 \%$ in $\mathrm{Mg}$ $6.2 \mathrm{~mol} \% \mathrm{Li}$ alloys $(\varepsilon=3.6 \%)$ and $8 \%$ in $\mathrm{Mg}-11.7 \mathrm{~mol} \% \mathrm{Li}$ alloys $(\varepsilon=3.0 \%)$. Here, $\mathrm{Mg}-11.7 \mathrm{~mol} \% \mathrm{Li}$ alloys with the low frequency showed high ductility. Conversely, in $\mathrm{Mg}-$ $6.2 \mathrm{~mol} \% \mathrm{Li}$ alloys, the frequency was $50 \%$; however the area fraction of $\{10 \overline{1} 2\}$ twins in each grain was approximately $15 \%$, resulting in approximately $7.5 \%$ area fraction of the whole specimen. Also, the present $\mathrm{Mg}-\mathrm{Li}$ alloys had basal texture, as shown in Fig. 2. Strain caused by $\{10 \overline{1} 2\}$ twinning occurs parallel to basal planes, i.e., compressive strain occurs parallel to the tensile direction (RD). Even assuming that the strain caused by $\{10 \overline{1} 2\}$ twinning affects the ductility, the shear strain of $\{10 \overline{1} 2\}$ twin in $\mathrm{Mg}$ is $13 \%$ and the normal strain parallel to the basal plane calculated to be $6.8 \%$. Therefore, considering the area fraction of $\{10 \overline{1} 2\}$ twin, the amount of the strain caused by $\{10 \overline{1} 2\}$ twinning was estimated to be approximately $0.5 \%$, and the effect of $\{10 \overline{1} 2\}$ twinning on the ductility is quite limited in $\mathrm{Mg}-$ $6.2 \mathrm{~mol} \% \mathrm{Li}$ alloys.

Figure 6 shows the relationship between frequency of activated slips and nominal strain in pure magnesium, ${ }^{2)} \mathrm{Mg}-$ Li alloys and $\mathrm{Mg}-0.9 \mathrm{~mol} \% \mathrm{Y}$ alloys. ${ }^{2)} \mathrm{Here}$, slip frequency was defined as the ratio of the number of grains with slip lines to the number of observed grains. The results on $\mathrm{Mg}-$ $0.9 \mathrm{~mol} \% \mathrm{Y}$ alloys are also shown for comparison since the ductility was similar to that in $\mathrm{Mg}-11.7 \mathrm{~mol} \% \mathrm{Li}$ alloys. The frequency of BS was the highest and approximately $50 \%$ at a failure strain of approximately $4.0 \%$ in pure magnesium. Non-basal slips were also activated; however, each frequency was a few percent. $\mathrm{Mg}-0.9 \mathrm{~mol} \% \mathrm{Y}$ alloys with high ductility were reported to have high frequency of each slip system $(\varepsilon=12.5 \%){ }^{2)}$ especially, BS frequency was extremely high at $90 \%$ or more. Conversely, BS frequency was $30-40 \%$ in $\mathrm{Mg}-\mathrm{Li}$ alloys and was lower than those in both pure magnesium and $\mathrm{Mg}-0.9 \mathrm{~mol} \% \mathrm{Y}$ alloys. Both FPCS and PS frequencies in $\mathrm{Mg}-\mathrm{Li}$ alloys were higher than those in $\mathrm{Mg}-$ 0.9 mol\%Y alloys. Also, FPCS showed the highest frequency among non-basal slips in Mg-Li alloys. Both FPCS and PS (a) $\mathrm{Mg}-6.2 \mathrm{~mol} \% \mathrm{LI}$

(b) $\mathrm{Mg}-11.7 \mathrm{~mol} \% \mathrm{Li}$

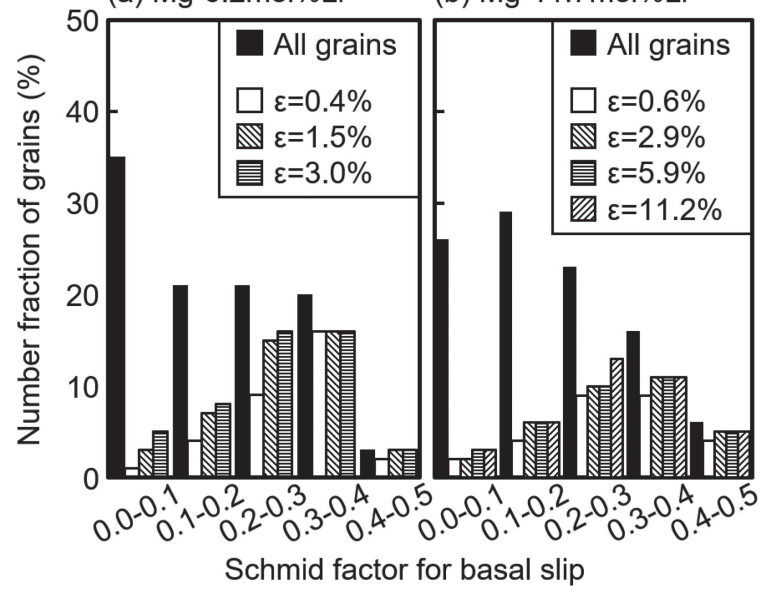

Fig. 7 Number fraction of grains where basal slips were activated as a function of Schmid factor for basal slips in (a) $\mathrm{Mg}-6.2 \mathrm{~mol} \% \mathrm{Li}$ and (b) Mg-11.7 mol\%Li alloys.

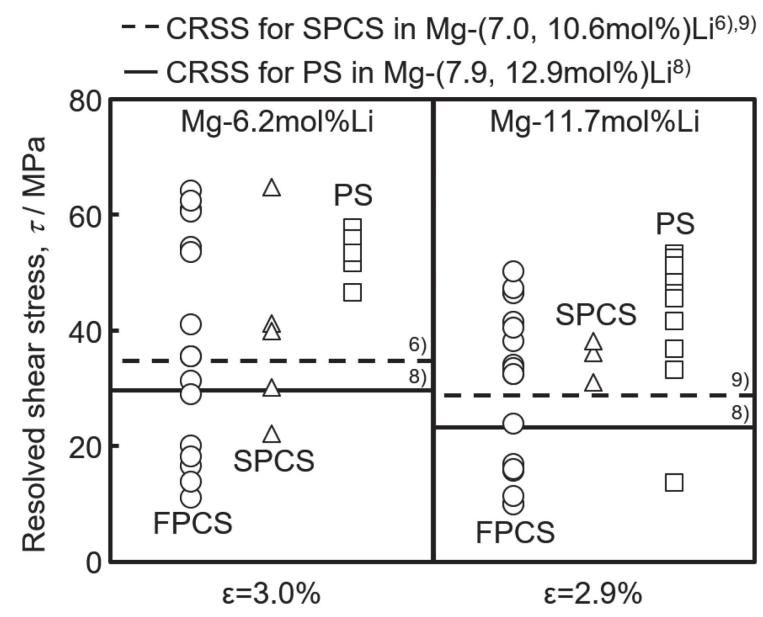

Fig. 8 Resolved shear stresses (RSSs) for non-basal slips at a nominal strain of approximately $3.0 \%$ in $\mathrm{Mg}-6.2 \mathrm{~mol} \% \mathrm{Li}$ and $\mathrm{Mg}-11.7 \mathrm{~mol} \% \mathrm{Li}$ alloys.

frequencies increased with increasing lithium content but not SPCS.

Figure 7 shows changes in the number fraction of grains where basal slips were activated at any strain as a function of Schmid factor for basal slip at intervals of 0.1 in (a) $\mathrm{Mg}-$ $6.2 \mathrm{~mol} \% \mathrm{Li}$ and (b) $\mathrm{Mg}-11.7 \mathrm{~mol} \% \mathrm{Li}$ alloys. Here, the black bars shows the number fraction of all grains analyzed by EBSD before the tensile tests; the highest Schmid factor for BS in each grain was used for the sorting. Therefore, tensile specimens before the tests had many grains with the small Schmid factor for BS because of its basal texture. The other bars show the number fraction of grains where BS was activated at each tensile strain. During the tensile test, BS activation started to occur in grains with relatively high Schmid factors for BS and then occurred in descending order, showing that BS activation depends on Schmid's law.

Figure 8 shows the resolved shear stresses (RSSs) for non-basal slips at a nominal strain of approximately $3.0 \%$ in $\mathrm{Mg}-\mathrm{Li}$ alloys. Here, assuming uniaxial stress, RSS was calculated using Schmid factor for activated slip systems and 
flow stress. Therefore, the RSS may be different from the actual shear stress loading on slip planes. Dashed lines in Fig. 8 indicate CRSS for SPCS in Mg-Li alloys; the CRSSs were calculated using the yield stress obtained from [1120] tensile tests of $\mathrm{Mg}-\mathrm{Li}$ alloy single crystals reported by Ando et al.: ${ }^{69}$ ) approximately $36 \mathrm{MPa}$ in $\mathrm{Mg}-7.0 \mathrm{~mol} \% \mathrm{Li}$ alloys and $29 \mathrm{MPa}$ in $\mathrm{Mg}-10.6 \mathrm{~mol} \% \mathrm{Li}$ alloys. Solid lines in Fig. 8 indicate CRSSs for PS: approximately $30 \mathrm{MPa}$ in $\mathrm{Mg}-7.9$ mol\%Li alloys ${ }^{8)}$ and $24 \mathrm{MPa}$ in $\mathrm{Mg}-12.9 \mathrm{~mol} \% \mathrm{Li}$ alloys. ${ }^{8)}$ Therefore, RSSs higher than CRSSs were found to apparently load on slip planes in most grains where SPCS and PS were activated in $\mathrm{Mg}-\mathrm{Li}$ alloys. Here, CRSS for FPCS in $\mathrm{Mg}-\mathrm{Li}$ alloys remains unclear, but must be higher than that for SPCS since $\mathrm{Mg}-\mathrm{Li}$ alloy single crystals yielded due to $\mathrm{SPCS}^{6,9)}$ in [1120] tensile tests. Therefore, in more than half the number of grains where FPCS were activated, FPCS would be activated at RSSs below the CRSS. Here, Ando et al. ${ }^{6,9)}$ reported that $\mathrm{Mg}-\mathrm{Li}$ alloy single crystals yielded due to SPCS and showed work hardening in [1120] tensile tests. Therefore, lines indicating CRSS for SPCS in Fig. 8 must be raised up when the strain of approximately $3 \%$ was considered. Hence, FPCS can be activated at RSSs below the CRSS in more grains. Also, slip lines caused by BS were observed in the grain next to the grain where FPCS was activated. Therefore, the stress concentration near grain boundaries by $\mathrm{BS}$ results in that FPCS is apparently activated at RSSs below the CRSS.

\section{Discussion}

Effects of lithium addition on mechanical properties and slip systems will be discussed below. $0.2 \%$ proof stress increased in $\mathrm{Mg}-6.2 \mathrm{~mol} \% \mathrm{Li}$ alloys but decreased in $\mathrm{Mg}-$ $11.7 \mathrm{~mol} \% \mathrm{Li}$ alloys, compared to pure magnesium, as shown in Fig. 4. Figure 9 shows relationship between CRSSs and content of alloy elements in pure magnesium, ${ }^{10-12)} \mathrm{Mg}-$ $\mathrm{Li}^{6-12)}$ and $\mathrm{Mg}-\mathrm{Y}^{2,13)}$ alloys. When lithium was added, CRSS for $\mathrm{BS}$ increased in $6.6 \mathrm{~mol} \%$ addition; ${ }^{7)}$ however, it barely changed even in 15.0 mol\% addition. ${ }^{7)}$ Conversely, CRSSs for both PS and SPCS decreased with increasing lithium

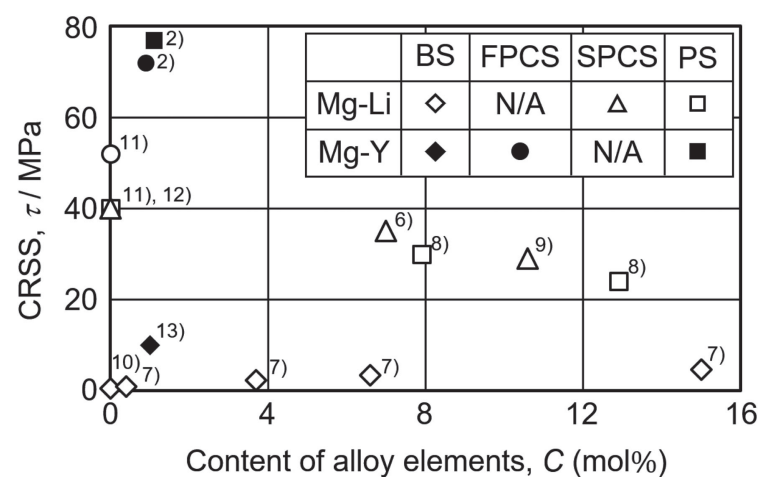

Fig. 9 Relationship between CRSSs and content of alloy elements in $\mathrm{Mg}-$ $\mathrm{Li}$ and $\mathrm{Mg}-\mathrm{Y}$ alloys.

content. Therefore, $0.2 \%$ proof stress of $\mathrm{Mg}-6.2 \mathrm{~mol} \% \mathrm{Li}$ alloys increases by the increase in CRSS for BS, while $0.2 \%$ proof stress of $\mathrm{Mg}-11.7 \mathrm{~mol} \% \mathrm{Li}$ alloys decreases by the significant decrease in CRSSs for non-basal slips.

Figure 10 shows schematic illustrations of texture, tensile properties and types of slip systems in rolled pure magnesium and magnesium alloys, based on the results in this study. Lithium addition increased ductility of magnesium but decreased the strength. Here, Mg-11.7 mol\%Li alloys showed $20 \%$ ductility, and it was approximately the same as that in $\mathrm{Mg}-0.9 \mathrm{~mol} \% \mathrm{Y}$ alloys. ${ }^{2)}$ Rolled pure magnesium with strong basal texture shows high $0.2 \%$ proof stress since Schmid factor for BS is close to 0 as the unit cell shown in Fig. 10(a). On the other hand, the ductility is low due to the low activity of BS. Therefore, the tilt of basal planes from the tensile direction is key to increasing the ductility, as shown in Fig. 10(b). ${ }^{14)}$ However, when the basal planes tilt from the tensile direction, Schmid factor for BS increases, i.e., BS becomes more easily activated, resulting in that the ductility increases but strength decreases. Rikihisa et al. ${ }^{2)}$ reported that yttrium addition increases ductility without decreasing strength, as shown in Fig. 3. The cause of the high ductility resulted from that basal texture was weakened by yttrium addition ${ }^{2)}$ as shown in Fig. 10(c); activities of not (a) Rolled magnesium with basal texture
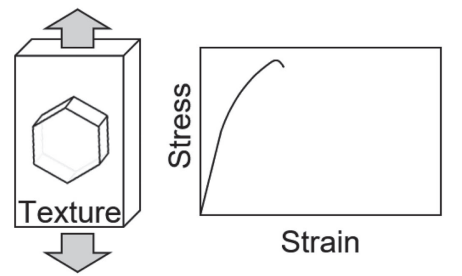

(b) Rolled magnesium with weak texture
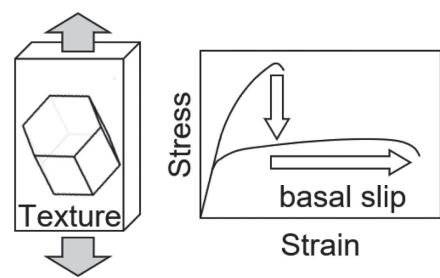

(c) Rolled $\mathrm{Mg}-0.9 \mathrm{~mol} \% \mathrm{Y}$
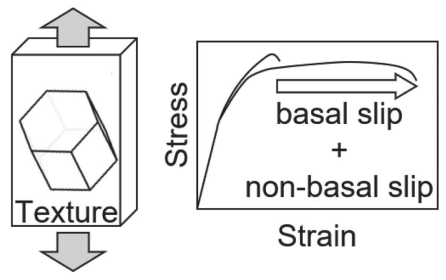

(d) Rolled Mg-11.7mol\%Li
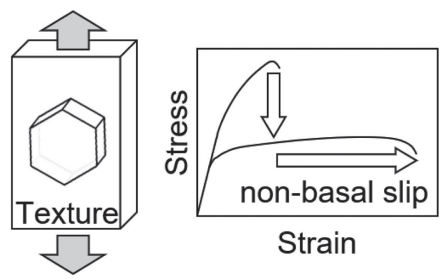

Fig. 10 Schematic illustrations of texture and tensile properties of rolled pure magnesium and magnesium alloys. 
only BS but also non-basal slips increased as shown in Fig. 6. However, yttrium addition weakened basal texture but increased CRSS for both BS and non-basal slips, resulting in the strength did not decrease, as shown in Fig. 9. On the other hand, $\mathrm{Mg}-\mathrm{Li}$ alloys showed strong basal texture, similar to that in rolled pure magnesium, and BS frequency was $30-40 \%$, as shown in Fig. 6. Therefore, the increase in the ductility was caused by higher non-basal slip activity than those in pure magnesium and $\mathrm{Mg}-0.9 \mathrm{~mol} \% \mathrm{Y}$ alloys. CRSS for BS slightly increased by lithium addition, but the strength decreased since CRSSs for non-basal slips greatly decreased. Here, in both $\mathrm{Mg}-\mathrm{Li}$ and $\mathrm{Mg}-\mathrm{Y}$ alloys, the frequency of FPCS and PS was high among non-basal slips. Rikihisa et $a .^{2)}$ reported that $\mathrm{Mg}-1.2 \mathrm{~mol} \% \mathrm{Y}$ alloys showed a lower ductility compared to $\mathrm{Mg}-0.9 \mathrm{~mol} \% \mathrm{Y}$ alloys and the frequency of PS was higher than those of FPCS and SPCS. Therefore, they concluded that FPCS activation is required to improve ductility. Frequencies of FPCS and PS in the present $\mathrm{Mg}-\mathrm{Li}$ alloys are approximately the same; however, the area with slip lines caused by FPCS was wider than that by PS, as shown in Fig. 5. Therefore, the contribution of FPCS is high in deformation of Mg-Li alloys. Which slip system contributes to increasing ductility will be discussed in the near future.

\section{Conclusions}

Tensile tests of rolled $\mathrm{Mg}-6.2 \mathrm{~mol} \% \mathrm{Li}$ and $\mathrm{Mg}-11.7$ mol\%Li alloys were carried out to clarify the relationship between mechanical properties and activities of slip systems. Main results are as follows:

(1) Ductility increased but tensile strength decreased, with increasing lithium content.

(2) Frequency of non-basal slips increased with increasing lithium content. First order pyramidal $\langle c+a\rangle$ slip showed the highest frequency among non-basal slips in $\mathrm{Mg}-\mathrm{Li}$ alloys.

(3) Frequency of basal slip in $\mathrm{Mg}-11.7 \mathrm{~mol} \% \mathrm{Li}$ alloys were similar to that in pure magnesium. Frequency of non-basal slips in $\mathrm{Mg}-11.7 \mathrm{~mol} \% \mathrm{Li}$ alloys was higher than that in $\mathrm{Mg}-0.9 \mathrm{~mol} \% \mathrm{Y}$ alloys, indicating that activation of non-basal slips improved ductility in $\mathrm{Mg}-$ $11.7 \mathrm{~mol} \% \mathrm{Li}$ alloys.

(4) Lithium addition decreased critical resolved shear stresses for non-basal slips, resulting in decreasing tensile strength.

\section{REFERENCES}

1) S. Sandlöbes, S. Zaefferer, I. Schestakow, S. Yi and R. GonzalezMartinez: Acta Mater. 59 (2011) 429-439.

2) H. Rikihisa, T. Mori, M. Tsushida, H. Kitahara and S. Ando: Mater. Trans. 58 (2017) 1656-1663.

3) S.R. Agnew, M.H. Yoo and C.N. Tome: Acta Mater. 49 (2001) 42774289.

4) Y. Chino, M. Kado and M. Mabuchi: Mater. Sci. Eng. A 494 (2008) 343-349.

5) J. Bohlen, M.R. Nürnberg, J.W. Senn, D. Letzig and S.R. Agnew: Acta Mater. 55 (2007) 2101-2112.

6) S. Ando, M. Tanaka and H. Tonda: Mater. Sci. Forum 419-422 (2003) 87-92.

7) H. Yoshinaga and R. Horiuchi: Trans. JIM 4 (1963) 134-141.

8) A. Ahmadieh, J. Mitchell and J.E. Dorn: Trans. Metall. AIME 233 (1965) 1130-1138.

9) S. Ando and H. Tonda: Mater. Trans. JIM 41 (2000) 1188-1191.

10) S. Miura, S. Imagawa, T. Toyoda, K. Ohkubo and T. Mohri: Mater. Trans. 49 (2008) 952-956.

11) S. Ando, K. Nakamura, K. Takashima and H. Tonda: J. JILM 42 (1992) $765-771$.

12) J.F. Stohr and J. Poirier: Philos. Mag. 25 (1972) 1313-1329.

13) A. Kula, X. Jia, R.K. Mishra and M. Niewczas: Int. J. Plast. 92 (2017) 96-121.

14) X. Huang, K. Suzuki, A. Watazu, I. Shigematsu and N. Saito: J. Alloy. Compd. 470 (2009) 263-268. 